\title{
Emilia Mrozińska
}

Nicolaus Copernicus University in Toruń, Poland

\section{Report from the Conference "The Local Government Dimension of the Integration Process between Poland and the European Union" (March 31, 2014)}

It has been already 10 years since Poland became a member of the EU. The past decade has been a decade of great changes. Our membership has been very fruitful and resulted in improving our economy due to the funds from the EU. The EU membership also changed our mentality. It has been also a time when we pursued a very cautious foreign policy, we also showed our great ability in creating various alliances.

Taking into consideration all the changes that appeared in our country in order for us to gain the support of the population when making policies in accordance to the EU objectives we cannot forget about the informative politics. It is important to provide an easier access to the knowledge about the EU, which would allow a larger part of the Polish nation to access information on the EU directives as well as statistics regarding the EU initiatives. It is important to take into consideration a wider Polish audience as well as the very specific reader, having in mind for example the employees of local governments.

The conference was called: "The local government dimension of the integration process between Poland and the European Union" and it took place on the March 31, 2014 in the Burghers' Hall of the Torun Old Town Hall. It has been organised by the academics from the Nicolaus Copernicus University (Faculty of Political Sciences and International Studies) in collaboration with the European Commission Representation in Poland and the Institute of European Studies at the University of Warsaw.

The conference was a result of year long project initiated by the Institute of European Studies at the University of Warsaw in collaboration with the European Commission Representation in Poland as well as with other universities. The aim of the project is to organise academic conferences with the participation of the leading universities and organisations associated with academic institutions that achieved significant success in the research on the processes influencing the European integration. The objective of this project is to organise several such conferences.

The main issues discussed at the conference were problems connected to the difficulties faced by the employees of local governments and the quality of implementing new policies that are required by the development of new political dynamics within the current political status quo. 